\title{
Evaluation of knowledge, attitude, and practice about first aid of spinal injury among medical students in Saudi Arabia, 2018
}

\author{
Eradah Ali AlMarhoon', Renda Ali Alhabib ${ }^{2}$, Abdullah Ali Alshaalan ${ }^{3}$
}

1-Almaarefa university, 2-Unaizah College of medicine, 3-Prince Sattam Bin Abdulaziz University $\underline{\text { Abstract }}$

Background: Spinal cord injury (SCI) is always a medical emergency as it could lead to chronic painful conditions, permanent paralysis or even death. Objectives: Assessing the knowledge, attitude and practice (KAP) regarding the first aid of spinal injury in Kingdom of Saudi Arabia (KSA). Methods: A prospective randomized controlled study based on a questionnaire sheet that was conducted at Saudi Arabia, from March to July 2018. The study included 390 medical students randomly chosen from different faculties of medicine around KSA. Results: The level of knowledge was sufficient among $84.9 \%$ of medical students. The attitude of the medical students was good among most of the participants regarding calling help and starting CRP immediately, taking care while moving the patients and applying direct pressure on the side of bleeding. The level of practice among most of medical students was good toward patients with spinal injury even conscious or not. Conclusion: The KAP level was sufficient among medical students about first aid of spinal injury. The proper knowledge, positive attitude and practice skills towards first aid can make a significant difference in Saudi Arabia.

Keywords: Knowledge, Attitude, Practice, medical students, first aid, spinal injury, KSA

\section{Background}

First aid is defined as some simple and quick steps that can be performed outside the hospital without or with minimal medical equipment to save someone who in risk or relive hispain until the arrival of ambulance ${ }^{(1,}$ 2).

Spinal injury is a lethal clinical condition that can occur frequently among adults. The treatment is often difficult and resulted in high incidence of disabilities and death around the world ${ }^{(3)}$. The most effective management of spinal injury begins with adequate first aid and rehabilitation ${ }^{(4,5)}$.

Also, cervical spinal cord injury is a severe problem that alter the neurological function resulting in compromising the cardiovascular and respiratory systems (6-8) especially during the 3-8 hours.It must be managed properly within the accurate time otherwise; theseconditions could result in death. If not managed adequately in a timely manner, these conditions can be lifethreatening. The patient must be stable to avoid further damage thus the secure mobilization is an indispensable must for definitive treatment and recovery ${ }^{(9)}$.

Most of Universities teach bout handling emergencies in hospital and prehospital which could be lifesaving. Although, the adequate knowledge regarding the emergency handling at the site of emergency was found to be insufficient which is supposed to be very life wasting ${ }^{(\mathbf{1 0}, \mathbf{1 1})}$. Also, there is a lack of studies contributing the awareness of medical students regarding first aid thus, the practice of some junior doctors may be nonsatisfactorily ${ }^{(12,13)}$.

\section{Methods:}

\section{Study design:}

A prospective randomized controlled study based on a questionnaire sheet that was conducted at Saudi Arabia, from March to July 2018.

\section{Study population and sample size:}

The study included 390 medical students randomly chosen from different faculties of medicine around KSA. As 13 universitieswere randomly chosen from each district then 30 medical students from the $4^{\text {th }}, 5^{\text {th }}$ and $6^{\text {th }}$ curriculum were randomly chosen from each university.

Study

tools:

The study was based on a questionnaire sheet that was designed after conducting a systemic search on all online medical search engines then was tested in a pilot study among 50 medical students to be tested, modified and validated. The questionnaire was reviewed by supervisors and the committee of university.

\section{Ethical approval:}

The study was approved by the ethical committee of Faculty of medicine. All the included interns gave a written informed consent for approval on taking part in the study. 


\section{Statistical analysis:}

The data were processed using the Statistical Package for Social Sciences (SPSS, version 22) for windows.

\section{Results:}

Assessment of knowledge among medical students concerning first aid during spinal injury:

The study included 390 medical students from both genders.As for the first aid awareness among the participants, all of them knew when to suspect spinal injury wither by head injury evidence, neck or back pain and complains, inability to move neck and neck or back twisting. Also, more than half of them (78.7\%) knew that weakness, numbness or paralysis or lack of control of limbs; bladder or bowels are significant signs of spinal injury. As for the first aid, all of the participants had sufficient knowledge about the importance of immobilizing the patient with spinal injury. Also, 90.8\% knew about the damage and complications of mobilizing the spinal injury patient in improper way. However, only $35.6 \%$ of them had proper knowledge about the importance of reduction within the first few hours and its effect on neurological outcomes. About $91.9 \%$ of subjects knew properly the exact timing for complete management of injury that could be lifesaving. Also, $78.5 \%$ knew the proper way for moving the patient with spinal injury and all of them knew about the importance of CPR among spinal injury patients

\section{Table (1): Awareness level among participants (390):}

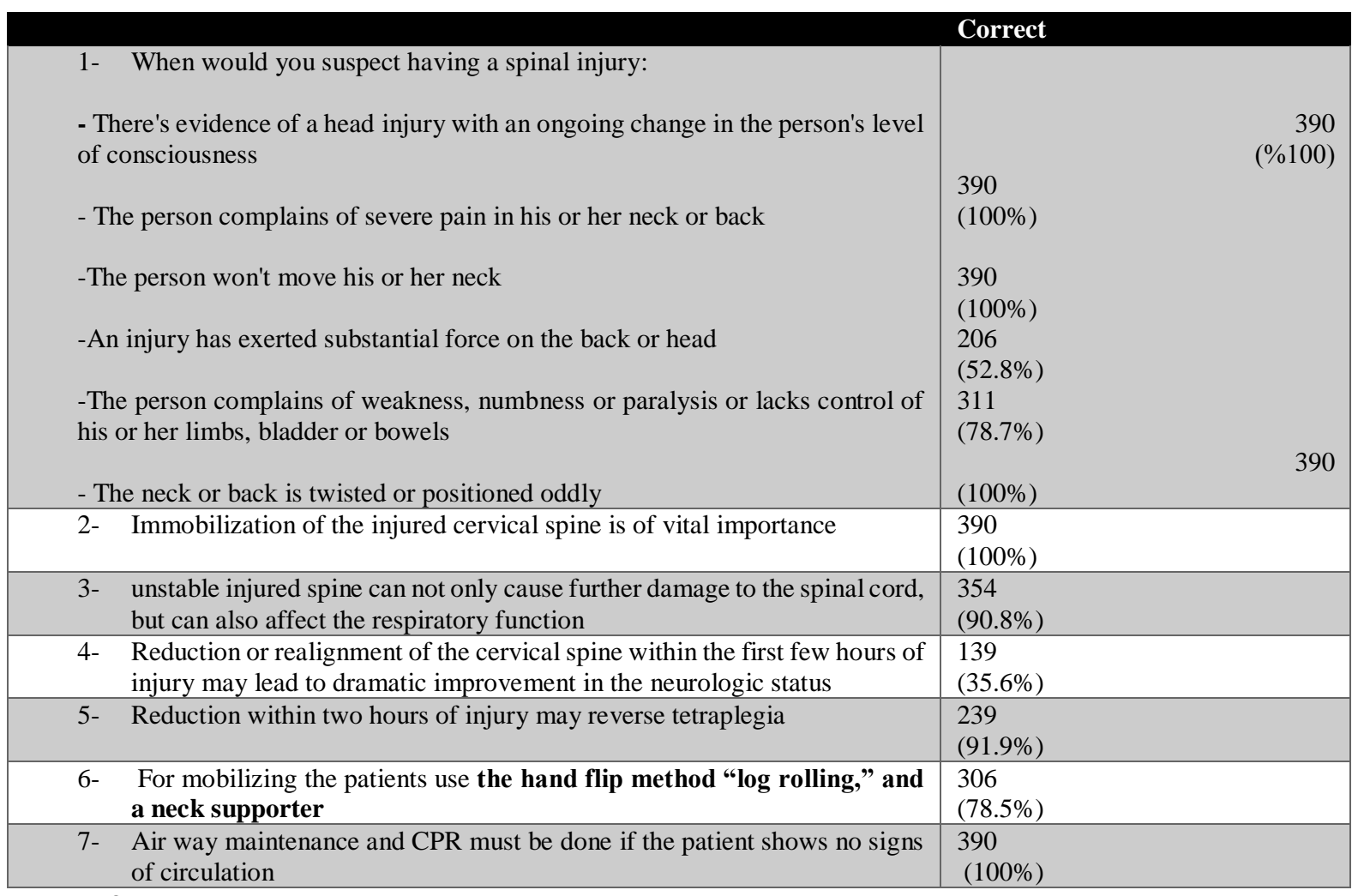

\section{Level of knowledge:}

The level of knowledge was sufficient among $84.9 \%$ of medical studentsand was insufficient among $15.2 \%$ of them (Table. 2).

Table (2): first aidlevel of knowledge

\begin{tabular}{|ll|l|l|}
\hline Knowledge level & Frequency & Percent (\%) \\
\hline & Good & 331 & 84.9 \\
& Poor & 59 & 15.2 \\
& Total & 390 & 100.0 \\
\hline
\end{tabular}

- Evaluating the attitude towards first aid: 
The attitude of the medical students was good among most of the participants regarding calling help and starting CRP immediately, taking care while moving the patients and applying direct pressure on the side of bleeding as presented in Table. 3 .

Table (3): Attitude of medical students toward first aid during spinal injury

\begin{tabular}{|l|l|l|}
$\begin{array}{l}\text { What will be the next step if you find a patient who is } \\
\text { unresponsive? }\end{array}$ & 71.3 \\
\hline $\begin{array}{l}\text { Check for no breathing and no pulse, call for help then start cardio } \\
\text { pulmonary resuscitation (CPR) }\end{array}$ & 278 & 3.1 \\
\hline Call for help directly. & 12 & 25.6 \\
\hline Start cardio pulmonary resuscitation (CPR). & 100 & \\
\hline $\begin{array}{l}\text { I would take spinal movement precautions in unconscious } \\
\text { trauma patients }\end{array}$ & 390 & 100 \\
\hline Yes & 0 & 0 \\
\hline No & & \\
\hline $\begin{array}{l}\text { In case of bleeding due to injury I apply direct pressure and } \\
\text { the injured limb is raised above the level of the heart }\end{array}$ & & 100 \\
\hline Yes & 390 & 0 \\
\hline No & 0 & \\
\hline
\end{tabular}

\section{Practice pattern of included subjects:}

The level of practice among most of medical students was good toward patients with spinal injury even conscious or not.

Table (4): practicepattern among medical students:

\begin{tabular}{|c|c|c|}
\hline & Yes & No \\
\hline $\begin{array}{l}\text { 1. I call ambulance and ask for help then begin first aid } \\
\text { intervention }\end{array}$ & $347(89 \%)$ & $43 \quad(11 \%)$ \\
\hline 2. I have practiced CPR before & $299(76.7 \%)$ & $91 \quad(23.3 \%)$ \\
\hline $\begin{array}{l}\text { 3. I take extreme care at all times to maintain alignment of } \\
\text { the head, neck and spine. }\end{array}$ & $365(93.6 \%)$ & $25 \quad(6.4 \%)$ \\
\hline $\begin{array}{l}\text { 4. Among unconscious patient/s, I place the unconscious } \\
\text { patient in recovery position supporting neck and spine } \\
\text { in a neutral position at all times to prevent twisting or } \\
\text { bending movements with maintain a clear and open } \\
\text { airway and a cervical collar }\end{array}$ & $286(73.3 \%)$ & $104(26.5 \%)$ \\
\hline $\begin{array}{l}\text { 5. If they're responsive: Reassure them and tell them not to } \\
\text { move }\end{array}$ & $390(100 \%)$ & $\begin{array}{ll}\mathbf{0} & (\mathbf{0 \%})\end{array}$ \\
\hline
\end{tabular}

\section{Discussion}

Restriction of the injured spine movement is significantly vital and could be lifesaving ${ }^{(9)}$. If it is ignored it could result in unstable damage to spinal cord, decline in respiratory and cardiac function. Thus, it is considered the first step of first aid to support the back and neck while moving the patient with spinal cord injury. Thus, study showed high level of KAP toward keeping the patient still, supporting him and decreasing the level of pain using special movement manner ${ }^{(14-16)}$.
This study aimed at establishing good knowledge about first aid of spinal cord injury among medical students to enhance the prehospital training and enabling the students to formulate first aid specifications which can save lives and decrease disabilities.

The positive attitude and the level of practice were adequate among most of the medical students which was associated with their high knowledge. The awareness and practice of CPR technique was high among the participants which could enhance the survival rate among 
patients till medical help arrives among most of the cases.

This study has some strength points as it is the first study to evaluate the KAP of medical students toward first aid of spinal injury which is a significant issue altering many lives with its high prevalence in KSA. This study has also some limitations including the included students were only from higher grades and there was a scanty of available online database considering the first aid during spinal injury.

\section{Conclusion:}

The KAP level was sufficient among medical students about first aid of spinal injury. The proper knowledge, positive attitude and practice skills towards first aid can make a significant difference in Saudi Arabia.

\section{References:}

1.Swetha C, Suchitra M and Sahana B (2015): A study on assessment of knowledge attitude and practices regarding first aid among nursing students. International Journal of Current Research, 7:1673-1675.

2.Joseph N, Kumar G, Babu Y et al. (2014): Knowledge of first aid skills among students of a medical college in mangalore city of South India. Ann Med Health Sci Res., 4:162-166.

3.Jazayeri SB, Beygi S, Shokraneh F et al. (2015): Incidence of traumatic spinal cord injury worldwide: a systematic review. European spine journal : official publication of the European Spine Society, the European Spinal Deformity Society, and the European Section of the Cervical Spine Research Society, 24:905-918.

4.Xue F, Xiong J, Zhang P et al. (2017): Prehospital and in-hospital first aid programs and specifications for spine and spinal cord injury in Beijing, China: study protocol for a prospective, multicenter, nonrandomized controlled trial. Asia Pacific Journal of Clinical Trials: Nervous System Diseases, 2:58.

5.Lee BB, Cripps RA, Fitzharris $M$ et al. (2014): The global map for traumatic spinal cord injury epidemiology: update 2011, global incidence rate. Spinal cord, 52:110-116.

6.Grabowski G, Cornett CA and Kang JD (2012): Esophageal and vertebral artery injuries during complex cervical spine surgery-avoidance and management. The Orthopedic clinics of North America, 43:63-74.

7.Helgeson MD, Gendelberg D, Sidhu GS et al. (2012): Management of cervical spine trauma: can a prognostic classification of injury determine clinical outcomes? The Orthopedic clinics of North America, 43:89-96.

8.Jubert $P$, Lonjon $G$ and Garreau de Loubresse C (2013): Complications of upper cervical spine trauma in elderly subjects. A systematic review of the literature. Orthopaedics \& traumatology, surgery \& research , 99:S301-312.

9.Kwon BK, Vaccaro AR, Grauer JN et al. (2006): Subaxial cervical spine trauma. The Journal of the American Academy of Orthopaedic Surgeons, 14:78-89.

10.Khan A, Shaikh S, Shuaib F et al. (2010): Knowledge attitude and practices of undergraduate students regarding first aid measures. JPMA The Journal of the Pakistan Medical Association, 60:68-72.

11.Tekian A (2002): Have newly graduated physicians mastered essential clinical skills? Medical education, 36:406-407.

12.Joseph N, Kumar GS, Babu YPR et al. (2014): Knowledge of First Aid Skills Among Students of a Medical College in Mangalore City of South India. Annals of Medical and Health Sciences Research, 4:162-166.

13.Tan EC, Severien I, Metz JC et al. (2006): First aid and basic life support of junior doctors: A prospective study in Nijmegen, the Netherlands. Medical teacher, 28:189-192.

14.Fransen BL, Hosman AJ, van Middendorp JJ et al. (2016): Pre-hospital and acute management of traumatic spinal cord injury in the Netherlands: survey results urge the need for standardisation. Spinal cord, 54:3438.

15.Oteir AO, Smith K, Stoelwinder J et al. (2017): Prehospital Predictors of Traumatic Spinal Cord Injury in Victoria, Australia. Prehospital emergency care : official journal of the National Association of EMS Physicians and the National Association of State EMS Directors, 21:583-590.

16.Robert AA and Zamzami MM (2013): Traumatic spinal cord injury in Saudi Arabia: a review of the literature. The Pan African medical journal, 16:104. 